DEMOGRAPHIC RESEARCH

VOLUME 34, ARTICLE 33, PAGES 927-942

PUBLISHED 2 JUNE 2016

http://www.demographic-research.org/Volumes/Vol34/33/

DOI: 10.4054/DemRes.2016.34.33

Descriptive Finding

\title{
More education, fewer divorces? Shifting education differentials of divorce in Taiwan from 1975 to 2010
}

\section{Yen-hsin Alice Cheng}

(C) 2016 Yen-hsin Alice Cheng.

This open-access work is published under the terms of the Creative Commons Attribution NonCommercial License 2.0 Germany, which permits use, reproduction \& distribution in any medium for non-commercial purposes, provided the original author(s) and source are given credit.

See http://creativecommons.org/licenses/by-nc/2.0/de/ 


\section{Table of Contents}

1 Introduction $\quad 928$

2 Prior research on educational differentials in divorce 929

$3 \quad$ Research design $\quad 930$

$4 \quad$ Findings 931

4.1 Period trends 931

4.2 Marriage outcomes implied by period and cohort divorce patterns 935

$5 \quad$ Conclusions and discussion $\quad 938$

$6 \quad$ Acknowledgments 939

References $\quad 940$ 


\title{
More education, fewer divorces? Shifting education differentials of divorce in Taiwan from 1975 to 2010
}

\author{
Yen-hsin Alice Cheng ${ }^{1}$
}

\begin{abstract}
BACKGROUND

While social gradient in divorce has been explored in many Western societies, this issue has received less attention in Asia.

OBJECTIVE

Few existing studies offer evidence of how educational gradients in divorce shift from positive to negative in Asia. This study explores changing divorce patterns by education for both sexes over the past four decades in Taiwan.

\section{METHODS}

Vital statistics of divorce since 1975 were used. Divorce rates were calculated and a synthetic cohort life table was constructed to estimate the proportions of unions that remain intact with the duration-specific divorce rates observed in 2010. A separate life table estimating the actual marriage survivorship for the 1998 marriage cohort was also presented.
\end{abstract}

\section{RESULTS}

As Taiwan went through industrialization, the period findings show that a reversal in educational differential in divorce from positive to negative is observed for both sexes. Now the least educated men and women have become more vulnerable to union instability. Finally, synthetic cohort life table estimates indicate substantial educational differences in the proportion of recent marriages ending in divorce.

\section{CONCLUSIONS}

The drastic increase in period divorce rates is accompanied by a reversal of educational gradient and expanding social inequality. The social gap in divorce rates expanded much faster among men than women across the years. Given that remarriage rates for the disadvantaged are lower than for the better educated, these patterns indicate that the disadvantaged are likely to spend an increasingly large proportion of their lives outside a marital union.

\footnotetext{
${ }^{1}$ Institute of Sociology, Academia Sinica, Taiwan. E-Mail: aliceyh@gate.sinica.edu.tw.
} 


\section{Introduction}

While Asia has largely been characterized as a region with relatively low divorce rates when compared to Western societies, a drastic rise in crude divorce rates has been reported in many East Asian societies over the past few decades (Dommaraju and Jones 2011). Countries like Japan, South Korea, China, and Singapore have all witnessed a two- to fivefold increase in the prevalence of divorce in less than four decades (United Nations Population Division 2009). In 2005, the crude divorce rate of Taiwan ranked the highest in East Asia, and it was only slightly lower than Hong Kong's in 2010. When compared internationally, the crude divorce rate of Taiwan in 2012 is only lower than those of the United States, Sweden, Belgium, Latvia, and Denmark, and is higher than those of many industrialized countries (OECD Social Policy Division 2015).

Existing research in Western societies has shown that divorce patterns vary not only across countries but also between social groups within a given society (Goode 1993; Martin 2011; Matysiak, Styrc, and Vignoli 2013). Divorce differentials point to the fact that marital instability and the undesirable consequences of divorce for adults and children are experienced differently across social lines. Prior studies have shown that the rapid increase in divorce has affected the socially disadvantaged more than the advantaged in most contemporary societies that have experienced high divorce prevalence (De Graaf and Kalmijn 2006; Härkönen and Dronkers 2006; Hoem 1997; Martin 2011). While changes in divorce patterns in Taiwan during the 20th century have been documented in prior research (Barclay 1954; Goode 1993; Thornton and Lin 1994), very little attention has been paid to the social variations in marital dissolution. This study aims to offer a more comprehensive investigation of the educational patterns of divorce over the past four decades in Taiwan for both men and women at the population level. Unpacking the social gradients in divorce risk is crucial, because such disparities tend to reinforce existing patterns of inequality across generations. This study plans to utilize vital statistics to describe period trends in divorce risk by sex and education from 1975 to 2010 . This study will also use synthetic cohort estimates to evaluate the implications of duration-specific divorce rates observed in 2010 on the outcomes of recent marriages with life table techniques. Cohort estimates of percentage of marriages survived by duration for the marriage cohort of 1998 will also be provided to reveal actual cohort experiences. 


\section{Prior research on educational differentials in divorce}

Different patterns of educational differentials in divorce have been reported in recent decades for Western societies (Blossfeld et al. 1995; De Graaf and Kalmijn 2006; Härkönen and Dronkers 2006; Jalovaara 2003; Matysiak, Styrc, and Vignoli 2013; Teachman 2002). While some studies found a positive relationship between women's education and marital instability (Blossfeld et al. 1995; De Rose and Di Cesare 2007; Poortman and Kalmijn 2002; Vignoli and Ferro 2008), others have shown a negative relationship (Boyle et al. 2008; De Graaf and Kalmijn 2006; Hoem 1997; Jalovaara 2003; Martin 2011; Teachman 2002). The general patterns revealed by Western research line up well with Goode's hypothesis (Goode 1993) that divorce differentials by education tend to be positive in countries where marital disruption is uncommon, and negative where divorce rates are much higher (Härkönen and Dronkers 2006; Matysiak, Styrc, and Vignoli 2013). A common trait of these studies is that they mainly focus on the characteristics of women, except for one Finnish study that investigated the association between men's education and marital instability (Jalovaara 2003). Overall, little is known about the traits of divorced men.

On the other side of the globe, substantial variations in recent patterns of marital dissolution have been observed in Asia. The Islamic Southeast Asian countries have been characterized by declining divorce rates until recent years, whereas the South Asian countries have experienced relatively constant and low divorce rates (Dommaraju and Jones 2011). For the more developed part of East Asia, family dissolution rates have been increasing over the past decades (Dommaraju and Jones 2011; Park and Raymo 2013; Raymo, Iwasawa, and Bumpass 2004; Yi and Deqing 2000). Educational differentials in marriage disruption have been reported to be negative in Japan and Korea for recent cohorts (Park and Raymo 2013; Raymo, Fukuda, and Iwasawa 2012; Raymo, Iwasawa, and Bumpass 2004).

As for educational variations of divorce in Taiwan, an earlier study by Lee (1984), making use of divorce registration data and vital statistics, showed that education was positively associated with divorce rates for both sexes between 1969 and 1981, and the positive educational gradient was much stronger for men than for women (Lee 1984). Another recent study by Chen (2012) investigated the educational gaps in marital disruption using the Women's Marriage, Fertility, and Employment Survey. A total of 14 waves of cross-sectional surveys between 1980 and 2006 were pooled together to examine divorce patterns by marriage cohort among 190,000 ever-married women (excluding widows) ages 25 to 60 . The findings indicated that while better educated women in earlier marriage cohorts (1940s to 1970s) were more likely to divorce, the risk of divorce increased faster and was much higher among the less educated women in later marriage cohorts. In turn, a reversal of educational gradient in divorce from positive to 
negative was first observed among women who married in 1980-1990 (Chen 2012). While Chen's study provides detailed analyses of the changing educational differentials in divorce behaviors for women who married between 1940 and 1990, the logistic regression analyses present only the relative risk of divorce for women from different educational backgrounds. The actual period prevalence rates of divorce and cohort divorce rates by education since 1980 have not been systematically examined in Taiwan. The implications of recent divorce rates for the survival rates of marriages are also unknown. In addition, no empirical research has addressed the union dissolution patterns among men by education across period and cohort in Taiwan.

The current study seeks to make use of the valuable and high-quality vital statistics data in Taiwan to offer a more comprehensive depiction of divorce patterns by education for both sexes. This paper aims to explore three research questions: 1) How have the educational gradients in divorce changed over the past four decades? 2) Do the changes in divorce patterns vary by sex? and 3) What are the implications of these changes in divorce risk on the outcomes of recently formed marriages?

\section{Research design}

Nationwide divorce counts by age and sex as well as by sex and education were compiled for the years between 1975 and 2010 from the Statistical Yearbooks. Along with population counts by age, sex, and marital status as well as by sex and education for ages 15 and over for the same time periods, these data will facilitate the calculation of the age patterns of divorce and general divorce rates per 1,000 population by education from 1975 to 2010. In addition, divorce counts by sex and education, along with population counts for those ages 15 and above by sex, education, and marital status from the 1980, 1990, 2000, and 2010 censuses will be used to calculate occurrence/exposure divorce rates by education in decadal interval. Finally, cross-tabulations of nationwide duration-specific divorce counts by age, sex, and education were also acquired for 2010 from the Department of Household Registration. Along with annual marriage count data by sex and education, duration-specific divorce rates based on divorce cases by marriage duration observed in 2010 were calculated for the construction of synthetic cohort divorce life tables for men and women separately, assuming mortality can be ignored. Due to data availability issues it is only possible to estimate marriage life table survivorship for a real cohort for those married in 1998, which is the first year for which complete marriage and divorce registration files can be obtained. 


\section{Findings}

\subsection{Period trends}

First, the age patterns of divorce across years are presented. As shown in Figure 1, the increases in divorce risk were slow and steady from 1975 to the early 1990s across ages for both sexes. Starting in the mid-1990s the pace of increase in divorce risk began to accelerate and eventually took off in the late 1990s. Young married adults under age 30 have been particularly exposed to a heightened risk of divorce in recent years, which is particularly true for women. Such rapid increases in divorce rates among younger men and women were largely due to a tremendous decline in the married population at younger ages (i.e., delayed marriage) that resulted in a smaller exposure population and a sustained increase in the number of divorces in these ages across years. To explore educational disparities in divorce risk from 1975 to 2010, general divorce rates were calculated. Educational levels were collapsed into two categories: tertiary (junior college and above) and nontertiary (high school and below). Figure 2 shows that divorce differentials by education used to be positive for men in the 1970s and 1980s. The positive gradient reversed in the early 1990s, and men with tertiary education were no longer more likely to divorce than their less educated counterparts. The bottom graph shows that the crossover occurred earlier for women than for men. In Figure 3, occurrence/exposure divorce rates reveal that the early 1980s appear to be the watershed when educational gradient in divorce shifted from positive to negative. In addition, the social gap in divorce risk for men has been expanding faster than that for women since the reversal of divorce trends. These findings indicate that the drastic increase in divorce risk over the past decades has been mainly driven by the tremendous growth in marital dissolution among the less educated. 
Figure 1: Age-specific divorce rates per 1,000 married population aged 15 and above by sex in Taiwan, 1975-2010
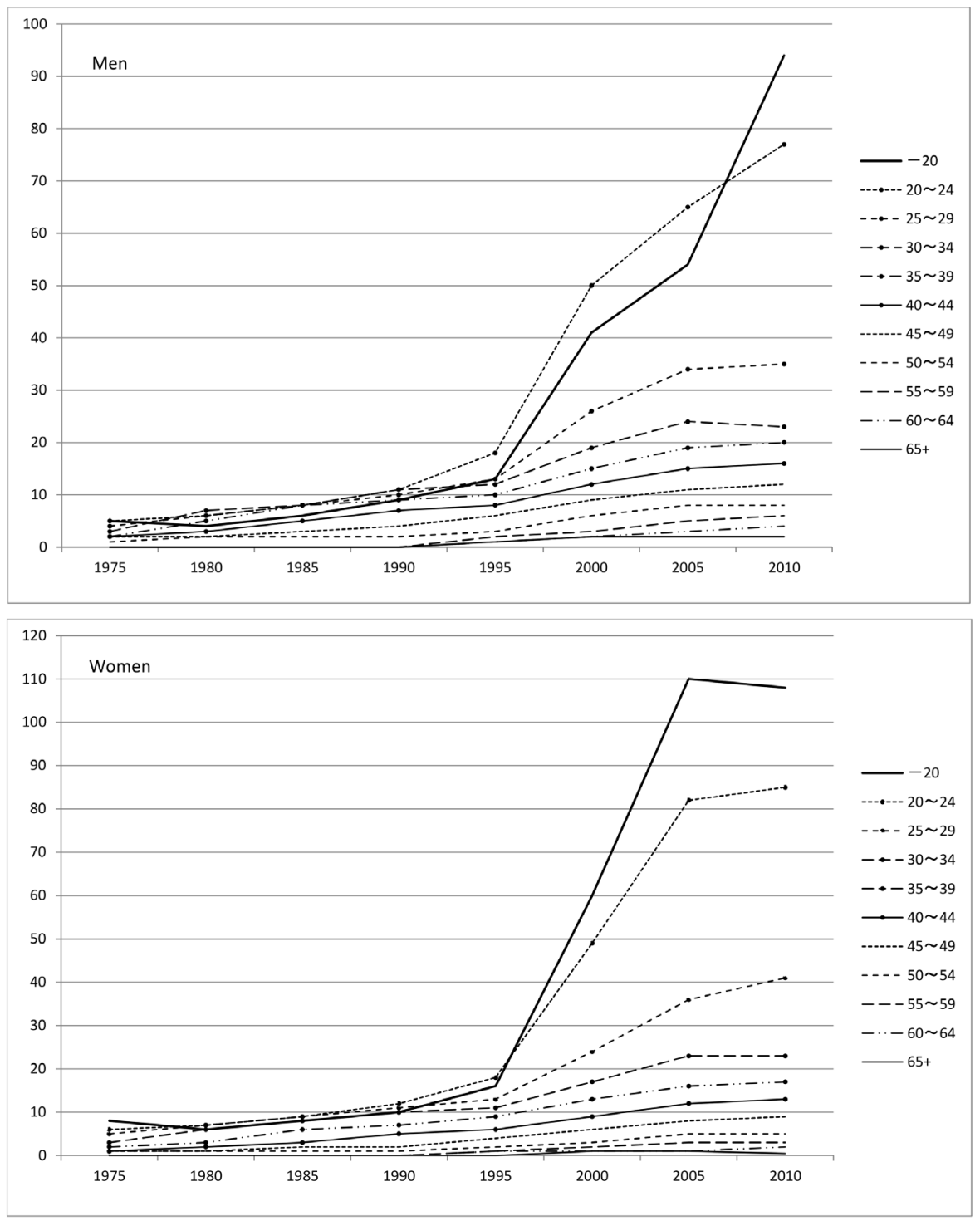

Source: Data calculated and released by the Department of Household Registration, Ministry of the Interior, Taiwan. http://www.ris.gov.tw/version96/population_01_C_06.html 
Figure 2: General divorce rate (per 1,000 population aged $15+$ ) by sex and by education in Taiwan, 1975-2012
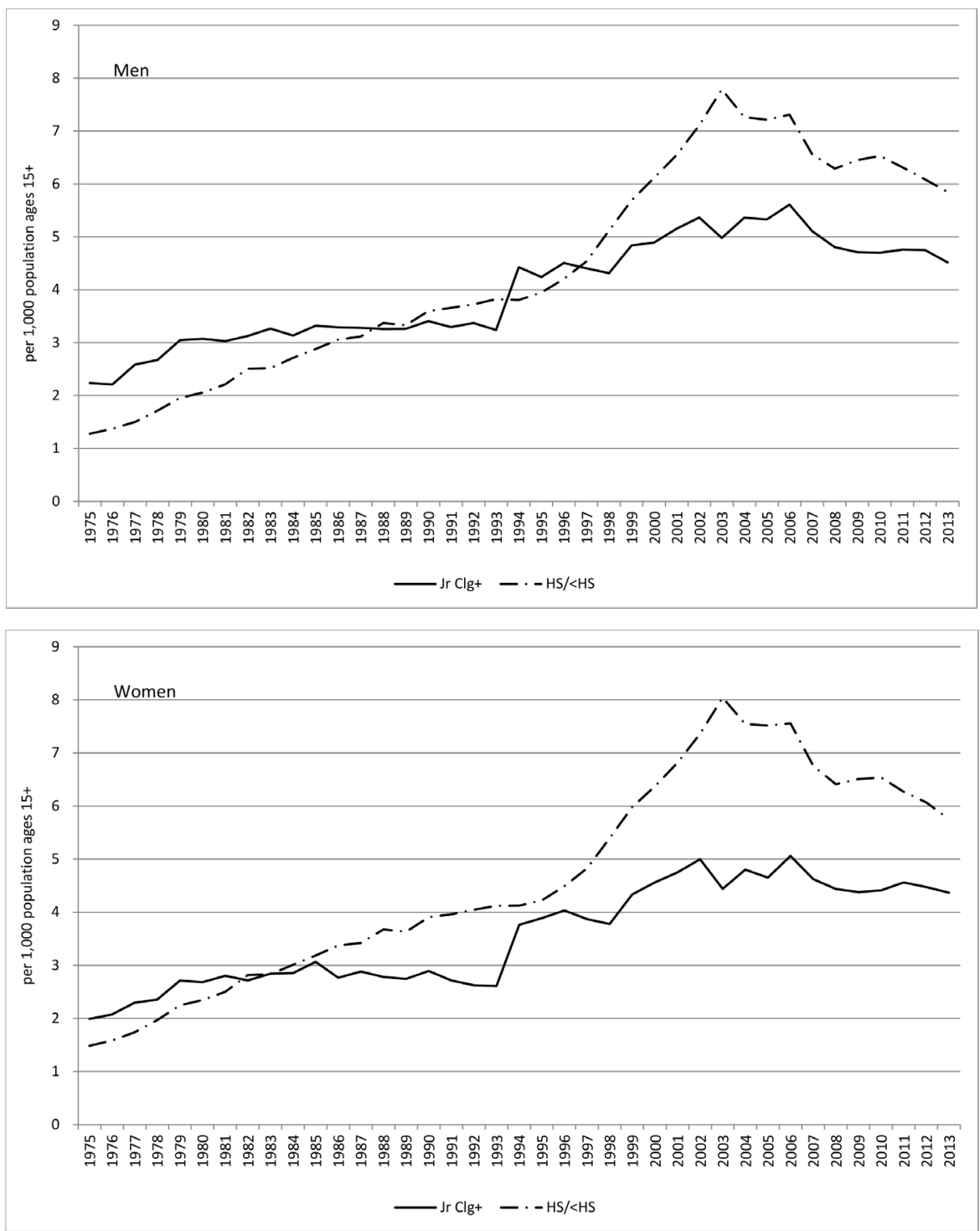

Note: Only data published after 1998 come with a separate educational category for college and above. The category "Jr. College+" (junior college and above) is used as the highest education category so that longer time-series data can be presented. 
Figure 3: Occurrence/exposure divorce rates per 1000 married men and women by education in Taiwan, 1980-2010
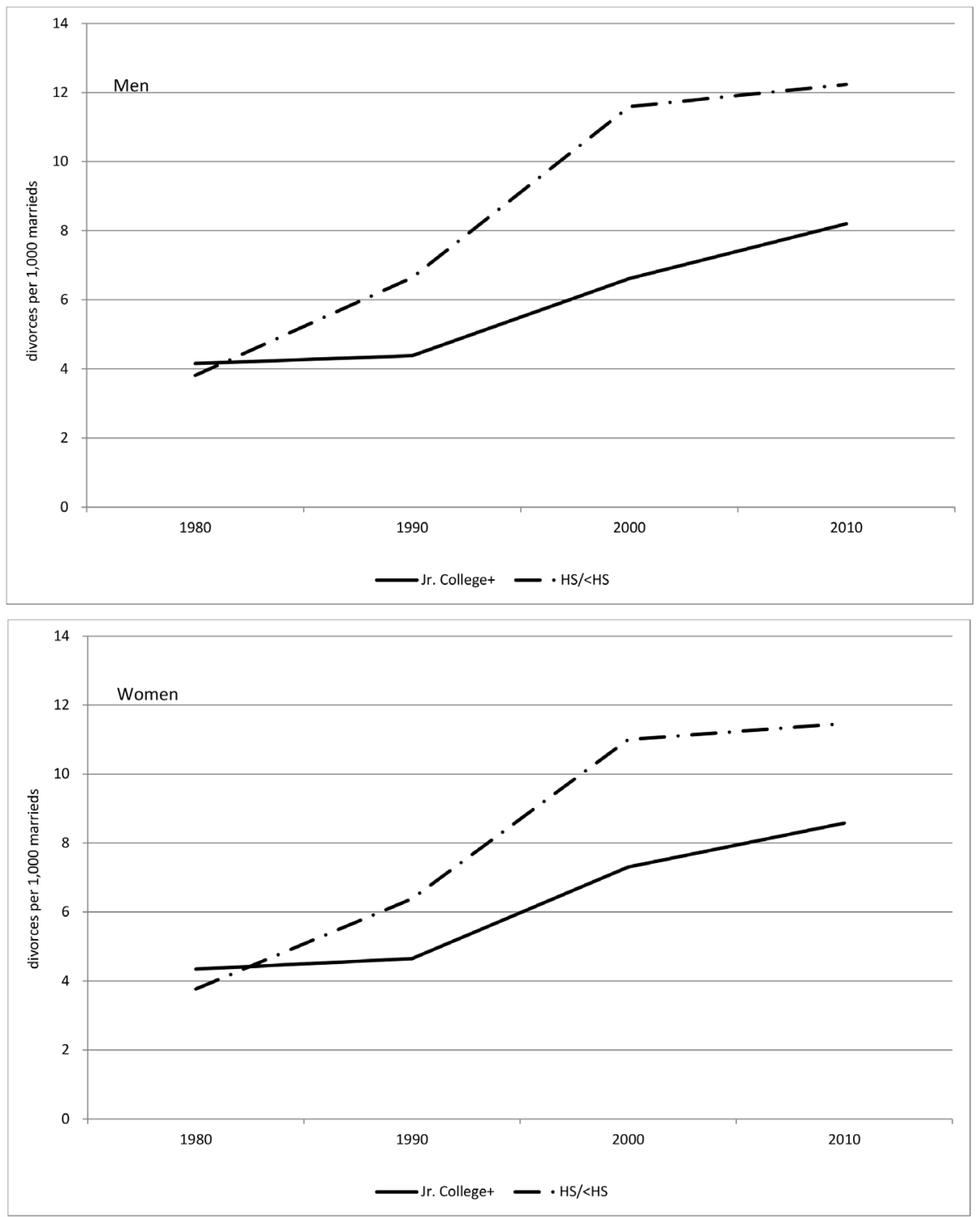

Note: Occurrence/exposure divorce rates are calculated by dividing the observed number of divorces in a given year by the total number of $15+$ population that are married in the same year. 


\subsection{Marriage outcomes implied by period and cohort divorce patterns}

To investigate the implications of the expanding educational gap in marital instability for recently formed marriages, duration-specific divorce rates by sex and education (i.e., less than high school, high school, and junior college and above) observed in 2010 were calculated. As shown in Figure 4, there are clear educational variations in the patterns of divorce risk. The peak of divorce risk is observed at one year after marriage for men and women with a high school degree or less, and the risk of marital disruption declined as the duration of marriage increased. Quite different from the less educated men and women, those with tertiary education had relatively low and constant divorce risk across almost the entire span of marriage duration. The risk of divorce for the better educated only declined substantially for marriages that lasted more than 20 years. The notion of the 'seven-year itch' does not seem to be supported by observed divorce rates for any group. One notable pattern is that while the risk of disruption is much higher among the less educated for marriages of shorter durations, the patterns of divorce risk change for marriages that lasted longer than 10 years: those with less than high school education and those with a high school degree have become less likely to end a marriage than their better educated counterparts.

Next, synthetic cohort life table estimates of the proportions of unions that remain intact for a hypothetical marriage cohort by marriage duration are presented by sex and education, using the 2010 duration-specific divorce rates discussed above. Overall, Figure 5 reveals that about $11 \%$ of marriages would dissolve within 5 years and $21 \%$ within 10 years. By the time of the $30^{\text {th }}$ anniversary, roughly $77 \%$ of marriages are still intact. When separated by sex and education, divorce risks are slightly higher for men than for women for all educational groups, and much higher among the less educated than among those with tertiary education. As shown in the graph, the educational gap in the proportions of intact marriages between those with and without tertiary education expands rapidly after one year of duration. About $16 \%-17 \%$ of marriages dissolve within five years for the less educated, but the comparable figures are less than $7 \%$ for those with tertiary education. The widest gap between these two groups is about $10 \%-$ $13 \%$ for unions that lasted 8 years and longer. For instance, the risk of union dissolution within 10 years is about $23 \%-26 \%$ for those without tertiary education and only $12 \%-$ $13 \%$ for the better educated. Since crude divorce rates have stabilized at around $2.4 \% 0-$ 2.5\% between 2012 and 2015 (a drop from the high plateau of 2.7\%- $2.9 \%$ in years 2002 to 2006), the life table estimates here will be underestimations only if another phase of drastic increase in marital dissolution resumes in the near future. In fact, when we tracked the marriage cohort of 1998, divorce rates at any given marriage duration shown in Figure 6 are much lower than those in Figure 5. For instance, less than 5\% of marriages dissolved within 5 years for the marriage cohort of 1998, whereas the 
comparable figure is more than $10 \%$ using the synthetic cohort estimates. Such a difference is mainly due to the fact that divorce rates rose dramatically after the new millennium in Taiwan. In other words, the various marriage cohorts that composed the life table in Figure 5 experienced higher divorce risk than the marriage cohort of 1998 in Figure 6. As for patterns of educational gradient, divorce risk is also lowest for the tertiary educated, although the group with the highest divorce risk here is those with a high school degree instead of the least educated for the 1998 marriage cohort.

\section{Figure 4: Duration-specific divorce rates by sex and by education observed in} 2010

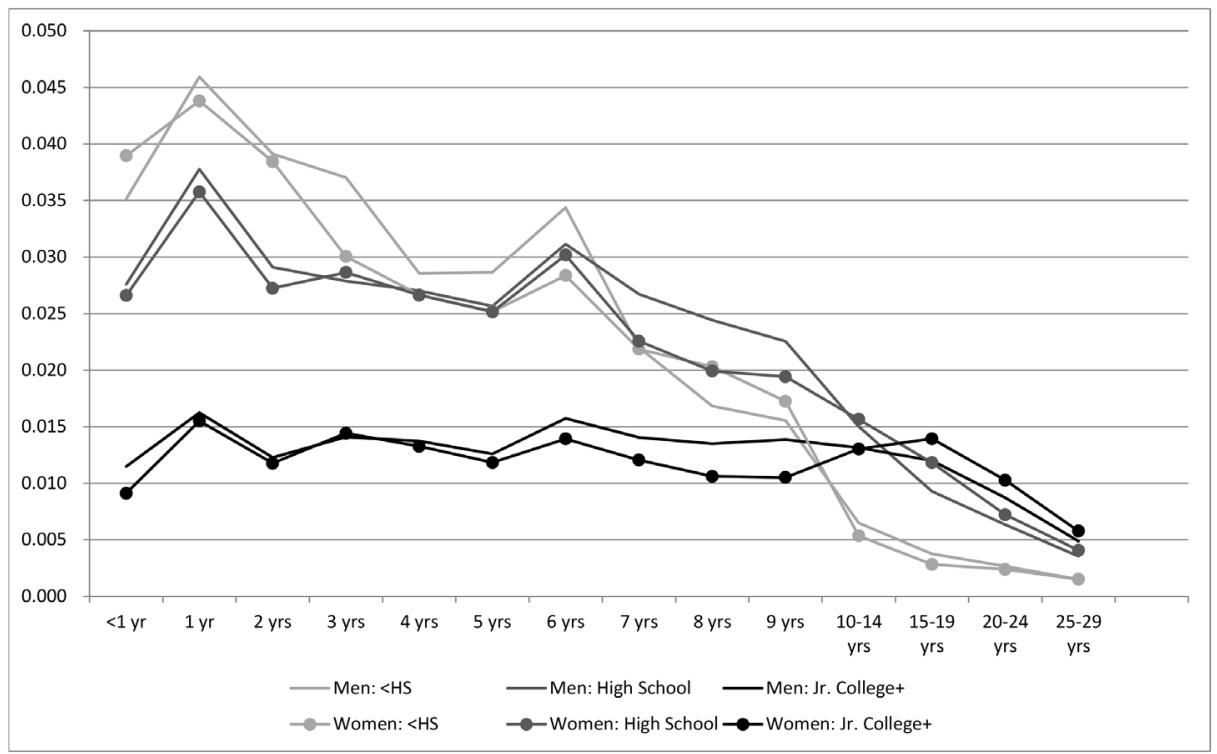

Source: Duration-specific divorce counts from divorce registration data are used as the numerator, and corresponding sizes of marriage cohorts are used as the denominator 
Figure 5: Synthetic cohort life table estimates of proportions of intact marriage (\%) for men and women across educational groups, based on 2010 observed duration-specific rates

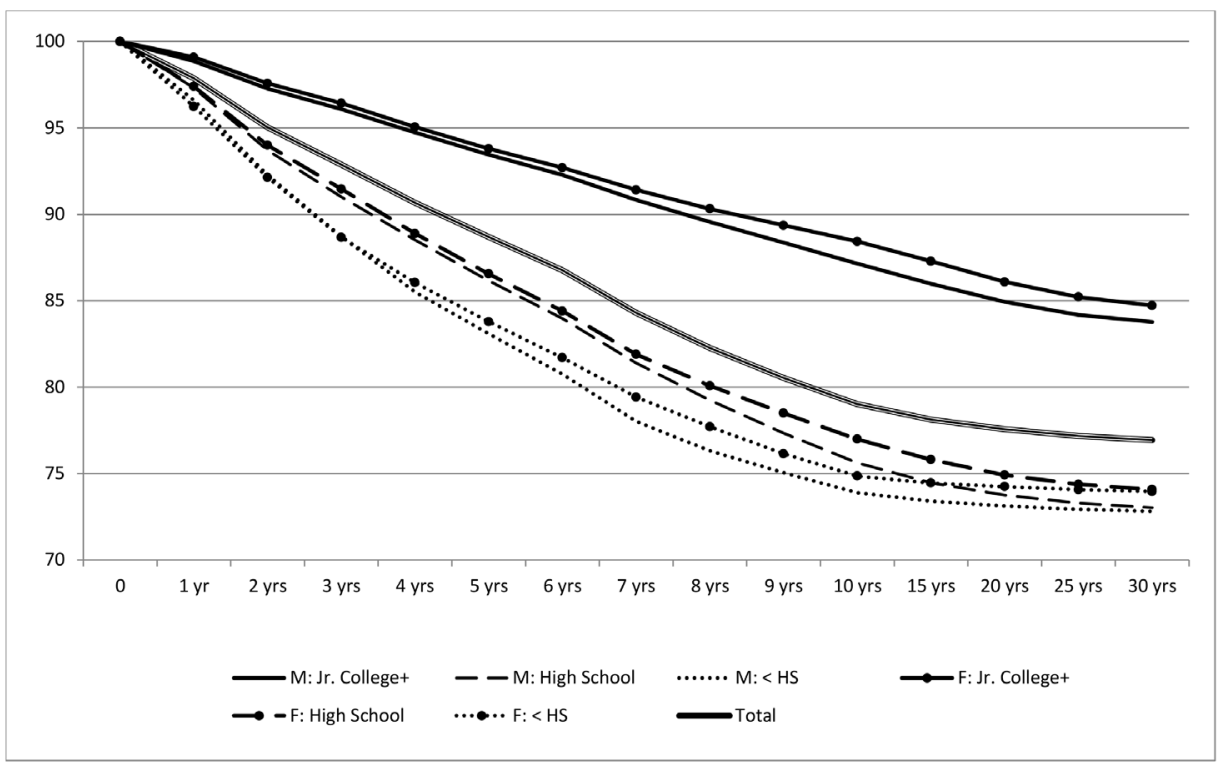

Notes: The curves for those with junior college and college+ education are very similar for both men and women and were thus combined as one category. 
Figure 6: Cohort life table estimates of proportions of intact marriage (\%) for men and women by education for the marriage cohort of 1998

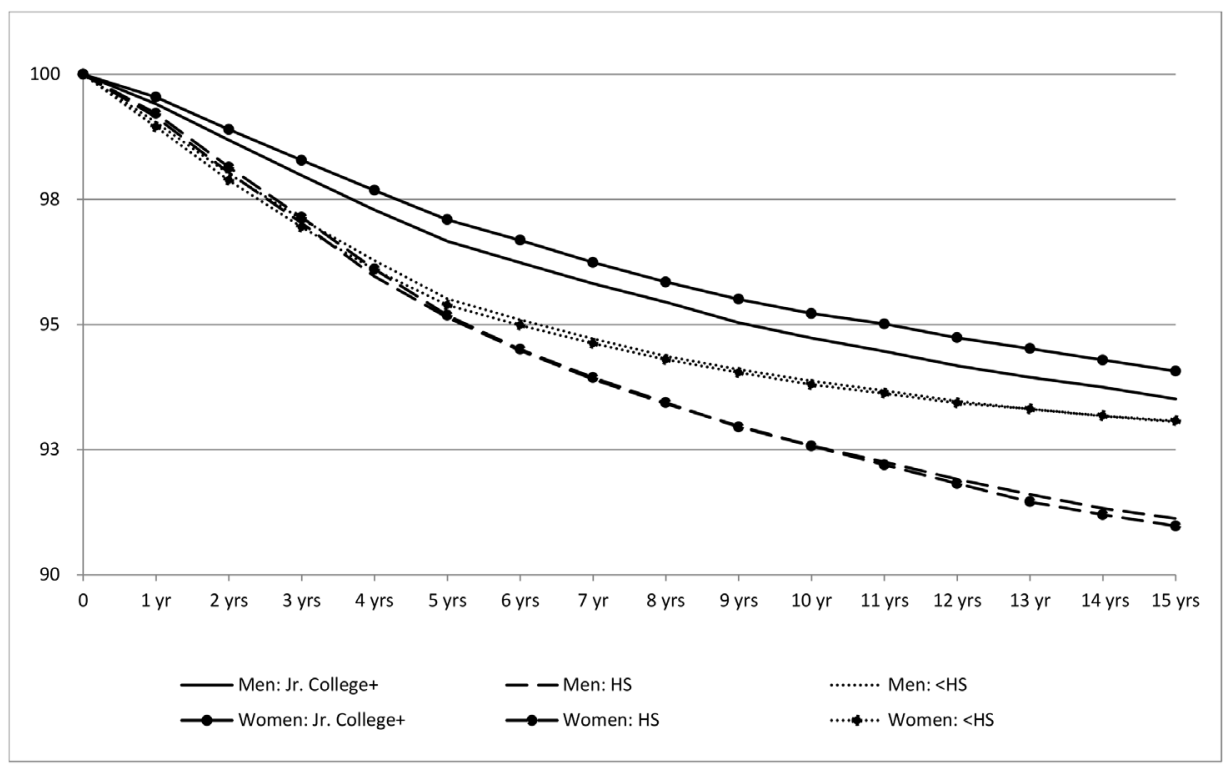

Note: Proportions of intact marriage were only calculated till 15 years after marriage because 2013 is the last year of data availability.

\section{Conclusions and discussion}

This paper set out to investigate the changing educational variations in divorce risk over the past few decades in Taiwan. As Taiwan went through industrialization and then postindustrialization in the $1990 \mathrm{~s}$, a drastic increase in crude divorce rates along with very low fertility and decreasing marriage rates has been the new social reality in recent years. Period analyses on general divorce rates and occurrence/exposure divorce rates both reveal an educational crossover in divorce rates for men and women, which led to a reversal in educational gradients of divorce from positive to negative. In particular, the drastic increase in divorce rates masks the fact that social inequality is expanding across educational lines: the less educated are becoming much more vulnerable to union instability and the divorce rates of disadvantaged men are higher than those of their female counterparts.

While most previous divorce research focused mainly on the characteristics of women, the results here suggest that the rising prevalence of divorce is causing greater 
social inequalities in marriage instability among men. Heightened divorce rates among less educated men can have unfavorable consequences for the adults and children involved in these unions. Indeed, a recent study shows that $97 \%$ of single-father families were caused by divorce (vs. 78\% of single-mother families) in 2006. In addition, a much larger share of single-father families were headed by low-income divorced fathers in 2006 than in 1998 (Cheng and $\mathrm{Wu}, 2016$ ). The economic advantage of single-father families over single-mother families has been declining. Furthermore, the levels of parental involvement with and awareness of children are much lower among less educated lone fathers than better educated lone fathers, whereas no educational differences are found among single mothers' parenting practices (Cheng and $\mathrm{Wu}, 2016$ ).

As marriage rates are declining much faster among less educated men and women than their more advantaged counterparts (Cheng 2014), the diverging outcomes of recent marriages across educational groups implied by the life table estimates warrant more attention. Within five years of marriage, less than $7 \%$ of unions dissolve for men and women with tertiary education, but about $16 \%-17 \%$ break up for those without a high school degree. Given that remarriage rates for the disadvantaged are lower than for the better educated (Ministry of the Interior 1975-2015), these patterns indicate that the less educated are spending an increasingly large proportion of their lives outside a marital union as single or previously married individuals. As less educated individuals have more limited human capital and fewer socioeconomic resources at their disposal, the consequences of heightened divorce risk and low remarriage rates will certainly have considerable impact on their life outcomes, because they will lack the extra safety net brought by family support in their old age. While policymakers and public discourses often focus on the disadvantages of single-mother families where the consequences of divorce are concerned, the results of this paper call for more attention to be paid to the well-being and development of all adults and children in disrupted families with limited resources.

\section{Acknowledgments}

This research was supported by a grant from the Ministry of Science and Technology of Taiwan under grant \#102-2410-H-001-073-MY2. An earlier version of this paper was presented at the 2014 Annual Meeting of the Population Association of America in Boston. The author thanks Dr. Robert Schoen as well as the editor and two reviewers for valuable comments on earlier versions of this paper. The author also thanks Fen-Chieh Felice Wu and Meng-Jung Emi Wu for excellent research assistance. 


\section{References}

Barclay, G.W. (1954). Colonial development and population in Taiwan. Princeton: Princeton University Press.

Blossfeld, H.-P., De Rose, A., Hoem, J.M., and Rohwer, G. (1995). Education, modernization, and the risk of marriage disruption in Sweden, West Germany, and Italy. In: Mason, K.O. and Jensen, A.-M. (eds.). Gender and family change in industrialized countries. Oxford: Clarendon Press: 200-222.

Boyle, P.J., Kulu, H., Cooke, T., Gayle, V., and Mulder, C.H. (2008). Moving and union dissolution. Demography 45(1): 209-222. doi:10.1353/dem.2008.0000.

Chen, W.-C. (2012). The changing pattern of educational differentials in divorce in the context of gender egalitarianization: The case of Taiwan. Population Research and Policy Review 31(6): 831-853. doi:10.1007/s11113-012-9250-9.

Cheng, Y.-h.A. (2014). Changing partner choice and marriage propensities by education in post-industrial Taiwan, 2000-2010. Demographic Research 31(33): 10071042. doi:10.4054/DemRes.2014.31.33.

Cheng, Y.-h.A. and Wu, F.-c. (2016). Going it alone and adrift: The socioeconomic profile and parental involvement of single-father and single-mother families in post-industrial Taiwan. Journal of Population Research 33: 147-172. doi:10.1007/s12546-016-9158-z.

De Graaf, P.M. and Kalmijn, M. (2006). Change and stability in the social determinants of divorce: A comparison of marriage cohorts in the Netherlands. European Sociological Review 22(5): 561-572. doi:10.1093/esr/jc1010.

De Rose, A. and Di Cesare, M. (2007). Gender and first union dissolution. In: Pinnelli, A., Racioppi, F., and Rettaroli, R. (eds.). Genders in the life course. Dordrecht: Springer: 167-184. doi:10.1007/978-1-4020-6002-1_7.

Dommaraju, P. and Jones, G. (2011). Divorce trends in Asia. Asian Journal of Social Science 39(6): 725-750.

Goode, W.J. (1993). World changes in divorce patterns. New Haven: Yale University Press.

Härkönen, J. and Dronkers, J. (2006). Stability and change in the educational gradient of divorce: A comparison of seventeen countries. European Sociological Review 22(5): 501-517. doi:10.1093/esr/jc1011. 
Hoem, J.M. (1997). Educational gradients in divorce risks in Sweden in recent decades. Population Studies 51(1): 19-27. doi:10.1080/0032472031000149696.

Jalovaara, M. (2003). The joint effects of marriage partners' socioeconomic positions on the risk of divorce. Demography 40(1): 67-81. doi:10.1353/dem.2003.0004.

Lee, M.-L. (1984). Social correlates of divorce in Taiwan. The Taiwanese Journal of Sociology (in Chinese) 8: 23-46.

Martin, S.P. (2011). Trends in marital dissolution by women's education in the United States. Demographic Research 15(20): 537-560. doi: 10.4054/DemRes.2006.15. 20.

Matysiak, A., Styrc, M., and Vignoli, D. (2013). The educational gradient in marital disruption: A meta-analysis of European research findings. Population Studies 68(2): 197-215. doi:10.1080/00324728.2013.856459.

Ministry of the Interior (1975-2015). Statistical yearbook of the Republic of China, 1975-2015. Taipei, Taiwan: Ministry of the Interior.

OECD Social Policy Division (2015). OECD family database. http://www.oecd.org/ social/family/database.htm.

Park, H., and Raymo, J.M. (2013). Divorce in Korea: Trends and educational differentials. Journal of Marriage and Family 75(1): 110-126. doi:10.1111/j.17 41-3737.2012.01024.x.

Poortman, A.R., and Kalmijn, M (2002). Women's labour market position and divorce in the Netherlands: Evaluating economic interpretations of the work effect. European Journal of Population/Revue européenne de Démographie 18(2): 175202.

Raymo, J.M., Fukuda, S., and Iwasawa, M. (2012). Educational differences in divorce in Japan. CDE working paper no. 2012-01. doi:10.4054/DemRes.2004.11.14.

Raymo, J.M., Iwasawa, M., and Bumpass, L. (2004). Marital dissolution in Japan: Recent trends and patterns. Demographic Research 11(14): 395-420.

Teachman, J.D. (2002). Stability across cohorts in divorce risk factors. Demography 39(2): 331-351. doi:10.1353/dem.2002.0019.

Thornton, A. and Lin, H.-S. (1994). Social change and the family in Taiwan. Chicago: University of Chicago Press. 
United Nations Population Division (2009). Crude divorce rates, world marriage data 2008. New York, NY: United Nations. http://www.un.org/ esa/population/publications/WMD2012/MainFrame.html.

Vignoli, D. and Ferro, I. (2008). Rising marital disruption in Italy and its correlates. Demographic Research 20(4): 11-36. doi:10.4054/DemRes.2009.20.4.

Yi, Z. and Deqing, W. (2000). A regional analysis of divorce in China since 1980. Demography 37(2): 215-219. doi:10.2307/2648123. 